\title{
Paradigmas para análises de constelação de gêneros
}

\author{
Evando Luiz e Silva Soares da Rocha \\ Universidade Estadual do Piauí \\ evevinho@gmail.com \\ https://orcid.org/0000-0002-1150-340X \\ José Ribamar Lopes Batista Júnior \\ Colégio Técnico de Floriano \\ ribas@ufpi.edu.br \\ https://orcid.org/0000-0002-4777-3305
}

Apresentar e discutir perspectivas sobre o modo como se definem os gêneros textuais demanda trabalho, perspicácia, acurado saber e habilidade para sintetizar conceitos e conhecimentos já construídos na área. É dessa forma que se recebe do Professor Júlio Araújo (Professor do Programa de Pós-Graduação em Linguística do Departamento de Letras Vernáculas da Universidade Federal do Ceará) a obra "Constelação de Gêneros: a construção de um conceito".

Trata-se de um trabalho que coloca em cena um vasto conjunto de visões e decisões teóricas que, de modo singular, dominaram a pesquisa de doutoramento do autor do livro que está aqui sendo resenhado. Por isso, há traços que filiam o autor, Professor Dr. Júlio Araújo, como estudioso e pesquisador da temática de gêneros ao percurso da Professora Bernardete Biasi-Rodrigues (orientadora de sua tese de doutorado) e do Professor Benedito Gomes Bezerra, seu contemporâneo na academia, a quem coube prefaciar a obra.

Com efeito, Júlio Araújo avança sobre os estudos de gêneros considerando, tanto os espaços acadêmicos nacionais, quanto às discussões tecidas em âmbito internacional. A organização do livro segue uma linha de discussões rigorosamente marcada pela acrescência teórica e a consequente interligação com o gênero "chat", objeto de estudo com que trabalhou em sua tese. As abordagens seguem dispostas em dez capítulos, cujas discussões são engatilhadas a partir de epígrafes que apontam para as posições teóricas assumidas pelos estudiosos e analistas de gêneros. Assim, as percepções do autor mostram-se interconectadas no imenso universo em que os gêneros se albergam ou se constelam.

O primeiro capítulo, "Colônia discursiva", é dedicado a justificar a decisão pelo termo "constelação de gêneros" que consta no título do livro. A discussão parte de um olhar autêntico advindo do lugar e do que o termo significa na ciência que estuda os astros e, consequentemente, o autor avança sobre a noção de agrupamentos de natureza das constelações. Com efeito, Júlio Araújo investe na exposição de apontamentos que justifiquem a decisão 
de estudar os gêneros sob a designação de constelação. A tensão e resistência entre diferentes maneiras de ver e estudar os mesmos fenômenos ou objetos (gêneros) são inscritas pelo autor ao longo dos quatro próximos capítulos.

Dessa forma, do segundo ao quinto capítulo, a proposta do autor revela a concepção de constelação de gênero em Bhatia, Marcuschi, Swales e Bakhtin, respectivamente. Ao construir seu percurso dialogando com os postulados de Bhatia ([1997] 2001), já no capítulo dois, "Constelação de gênero em Bhatia", Júlio Araújo evidencia que o pesquisador indiano elege a noção de propósito comunicativo para uma definição de constelação de gênero. Entretanto, o exame detalhado sugerido por Júlio Araújo expõe a fragilidade da noção cunhada por Bhatia para a constelação de gênero, uma vez que o critério do propósito comunicativo quando não obedecido, reflete a criação de subgêneros e não de uma constelação. Na verdade, esse segundo capítulo é o lugar das ponderações e questionamentos de Júlio Araújo em relação ao que Bhatia defende e credita ao propósito comunicativo em relação aos gêneros constelados.

A propósito da investida sobre o que postula Marcuschi (2000), o capítulo três, intitulado; "Constelação de gênero em Marcuschi" é tomado pelo debate de questões pertinentes à concepção de gêneros defendida na perspectiva marcuschiana e que não se encontram totalmente resolvidas. Dessa maneira, percebe-se a relevância dos estudos marcuschianos, mesmo diante de um quadro de discussões que o próprio Marcuschi não teve o tempo de aprofundar. Assim, ao torná-lo saliente, Júlio Araújo é consciente e cauteloso em suas reverberações.

Desse modo, conforme depreende-se da retomada feita pelo autor Júlio Araújo dos postulados marcuschianos, constata-se que uma constelação de gêneros em Marcuschi aparece quando da necessidade de caracterizar ou definir exemplares de gêneros considerando a forma e o formato e que constituam eventos ou subgêneros. Nesse caso, o autor considera problemático o fato de Marcuschi não ter esclarecido com propriedade o que são os eventos ou os subgêneros e tampouco ter apresentado um percurso metodológico consistente.

Embora o Professor Júlio Araújo considere que John Swales não seja caudatário de uma definição objetiva para constelação de gêneros, o foco da discussão proposta no quarto capítulo, "Constelação de gênero em Swales" , evidencia o trabalho de Swales (2004). Assim, sobre a definição de constelação de gêneros, Júlio Araújo destaca que essa noção não mobilizou de Swales maiores aprofundamentos.

O autor mostra que Swales trata dos gêneros constelados sob o que designa de hierarquias, cadeias, grupos e redes de gêneros. Mesmo que apresente uma logicidade dentro do espaço de interesse dos estudos de gênero na perspectiva swalesiana, as noções apresentadas para cadeias, grupos e redes de gêneros não são tão estáveis em outras esferas ou espaços de atividade humana. Além disso, sobre essa proposição, há discordâncias, conforme disposto nesse capítulo, pois Júlio Araújo reflete sobre a noção de hierarquia e sustenta que ela atravessa os demais termos apresentados, o que caracterizaria uma certa 
redundância na tipologia dada. Conforme se depreende, a investida sobre o trabalho de Swales permite reflexões sobre as distinções que esse autor estabeleceu entre os tipos de agrupamentos de gêneros e a proposição de Júlio Araújo em refinar o seu conceito de constelação de gêneros.

A perspectiva bakhtiniana é sempre um ponto saliente nos estudos sobre os gêneros. Sob efeito dessa consciência, no quinto capítulo, "Constelação de gêneros em Bakhtin", o autor traz um apanhado sobre o modo como Bakhtin ([1953] 2000, [1929] 2002) mobiliza conceitos que autorizam aos estudiosos de gêneros perceberem a noção de constelação de gênero implícita nas discussões que tece. Para tanto, nas situações propostas, o autor investe na discussão sobre os estudos bakhtinianos que tratam da transmutação que um determinado gênero sofre. A partir de então, visualiza e admite que a noção de constelação de gêneros em Bakhtin é inferencial. Certamente, essa é uma posição assumida por Júlio Araújo que amplia a compreensão sobre os trabalhos de Bakhtin para além do que é dado na tecitura ou na superfície dos postulados bakhtinianos.

"Constelando argumentos" é o sexto capítulo, constituído daquilo que o Professor Júlio polemiza em relação ao que os autores Bhatia, Marcuschi, Swales e Bakhtin discutiram em seus trabalhos e que se aproximam da noção de constelar gêneros. Diante das fragilidades epistêmicas encontradas em cada autor, no caso do empreendimento sobre constelação de gêneros, Júlio Araújo argumenta em favor de uma definição consistente, considerando em seu conceito a caracterização, a definição objetiva e o percurso metodológico que orienta as análises de gênero.

No sétimo capítulo, "Propondo trilhas", o autor avança sobre a apresentação do percurso teórico-metodológico que o autoriza definir constelação de gêneros, tornando relevantes os aspectos sobre os quais empreendeu ação questionadora. Certamente, a partir desse capítulo, a obra evolui do lugar de discussão para o de proposição. Logo, o autor não apresenta categorias estanques, mas eixos temáticos que convergem para constelar os gêneros. Esses eixos são: i) a(s) esfera(s) de comunicação em que tais gêneros se ambientam; ii) as marcas de sua formação genérica; iii) suas funções sociais dentro da constelação. Com base nesses três eixos, Júlio Araújo encaminha a construção de uma metodologia para as análises de constelações de gêneros, fornecendo percursos dinâmicos e bem orientados.

A noção de hipertextualidade e ambiência digital é uma abordagem cara para Júlio Araújo. Então, o oitavo capítulo, "A hipertextualidade da ambiência digital", é dedicado à atualização da noção de hipertextualidade no cerne do universo digital, sem abandonar a referência de onde emerge, que são os estudos bakhtinianos. Porém, Júlio Araújo situa a noção de hipertextualidade junto aos construtos hipermidiáticos disponibilizados pela recursividade da web. A rigor, o autor traz reflexões e definições que situam o termo hipertexto que, por meio da referência a Marcuschi (1999), especifica que não corresponde ao suporte ou ao gênero, mas à forma de organização. Além disso, considera que a hipertextualidade não é exclusividade dos ambientes digitais, mas um fenômeno que 
recai sobre qualquer tipo de texto e, por isso, a toma como uma categoria proativa de sua noção de constelação de gênero.

No nono capítulo, "A transmutação", a abordagem evidencia o fenômeno de transmutação de gêneros. Neste caso, o autor descreve a definição do termo construída em e por diferentes áreas do conhecimento. Logo, ao situar a concepção de transmutação nos estudos de gênero, Júlio Araújo considera que os conceitos já estão postos.

O autor demonstra ainda que transmutar comporta, de forma estrita, sentidos como: mudar, transformar, transportar, converte-se (ARAÚJO, 2021, p.79, grifos do original). Ao dispor o termo nos estudos de gêneros, o autor considera o longo percurso definido sobre os gêneros em Platão e Aristóteles, até Bakhtin, em uma abordagem de linguagem mais ampla, cuja ideia de transmutação é recorrente para explicar a constituição de certos gêneros. A rigor, Júlio Araújo filtra os conceitos que permeiam os estudos de gêneros em diferentes momentos da história e discute como tais conceitos possibilitam entender os processos de atualização que acompanham os gêneros.

Dessa maneira, a discussão evolui, à medida em que são dispostas visões sobre o fenômeno da transmutação de gênero, bem como o autor elucida a correlação com outros conceitos, como os casos, por exemplo, de miscelânea de gêneros, gêneros híbridos e captação de gêneros. Assim, visando clarear a noção de transmutação, admite-se que há transmutação quando um gênero muda de propósito comunicativo.

Já no décimo e último capítulo, "O propósito comunicativo", o ciclo de discussões chega à noção de propósito comunicativo à luz das reflexões bakhtinianas. Por extensão, o autor pontua como essa noção atua na atividade de constelar gêneros e evidencia as discussões postas por Bhatia, esclarecendo que há duas dimensões que possibilitam a compreensão de gêneros: uma é a psicológica, que admite os gêneros como ação de linguagem; e a outra é a sociológica, que os tomam como atividade de linguagem. Diante do quadro de discussões que ganham corpo na obra, Araújo assume que o propósito comunicativo deve ser tomado sob o enfoque dos construtos sociais. Embora o autor tenha posicionado o propósito comunicativo no lugar final das discussões, ele salienta que, para a sua noção de "constelação de gêneros", é fundamental que se tenha claro o trabalho com os três parâmetros: hipertextualidade, transmutação e propósito comunicativo.

No tópico de conclusões, construído a rigor das discussões evocadas, o autor aponta para referências comuns aos gêneros, tanto em sentido estrito quanto em relação às constelações de gêneros. Assim, Araújo reforça que é preciso organizar o estudo de constelações de gêneros em dois percursos no tocante ao propósito comunicativo, a saber: a visão geral sobre os grupos de gêneros e a visão mais específica, cujo foco é sobre determinado gênero constelado.

No final da obra, Júlio Araújo enfatiza que constelação de gêneros consiste em um agrupamento de situações comunicativas que comporta e compartilha características comuns quanto à esfera comunicativa, à constituição e ao propósito comunicativo. Ao situar o analista em uma abordagem metodológica sobre constelação de gênero, o autor 
aponta para o propósito comunicativo, a hipertextualidade e a transmutação. A propósito, essa obra do professor Júlio Araújo, pelo seu caráter instigante e reflexivo diante do quadro já estabelecido, ascende a importantes discussões no lastro de estudos de gêneros. Além disso, com o conceito e o percurso analítico que apresenta, ocupa um lugar merecido entre as leituras acadêmicas, fornecendo parâmetros e possibilidades de análises para os pesquisadores da área.

Certamente, o teor dessa obra nos aproxima das abordagens construídas no âmbito das escolas de tradição em estudos de gênero, como a angloamericana, a franco suíça e a australiana. E, pelo diálogo que estabelece com os postulados bakhtinianos e a abrangência dos ambientes digitais, o autor Júlio Araújo inscreve a obra "Constelação de gêneros: a construção de um conceito" como uma importante referência para a construção de novos olhares sobre os conceitos, classificações e percursos metodológicos que acrescentam novos paradigmas aos estudos de gêneros.

\section{REFERÊNCIAS}

ARAÚJO, Júlio. Constelação de gêneros: a construção de um conceito. - 1. ed. - São Paulo: Parábola, 2021. 